\title{
Silencing of Forkhead box D1 inhibits proliferation and migration in glioma cells
}

\author{
YUAN-FENG GAO ${ }^{1,2}$, TAO ZHU $^{1,2}$, XIAO-YUAN MAO ${ }^{1,2}$, CHEN-XUE MAO $^{1,2}$,

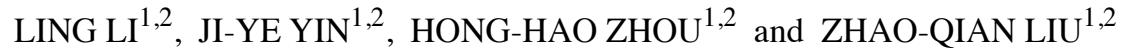 \\ ${ }^{1}$ Department of Clinical Pharmacology, Xiangya Hospital, Central South University, Changsha, Hunan 410008; \\ ${ }^{2}$ Institute of Clinical Pharmacology and Hunan Key Laboratory of Pharmacogenetics, \\ Central South University, Changsha, Hunan 410078, P.R. China
}

Received August 2, 2016; Accepted December 27, 2016

DOI: $10.3892 /$ or.2017.5344

\begin{abstract}
Despite the extensive role of Forkhead box transcription factors in the development and progression of various cancers, little is known about their role in glioma. We examined the expression and function of Forkhead box D1 (FOXD1) in glioma cell behavior and found that FOXD1 was upregulated and directly correlated with the glioma grade. Data analysis also revealed significant differences in FOXD1 expression for both gene expression profiles (GSE4290 and GSE7696) and the TCGA datasets. Additionally, decreased FOXD1 expression in U251 and U87 glioma cells caused a delay in cell growth and a disruption in colony formation. FOXD1 silencing also promoted generation of apoptotic bodies containing nuclear fragments. Cells with suppressed expression of FOXD1 markedly reduced glioma cell migration. Our results suggest that FOXD1 may serve as a novel regulator of glioblastoma cell behavior that may offer a novel target for gene targeted glioma therapies.
\end{abstract}

\section{Introduction}

Gliomas are the most malignant and common type of brain tumors (1). Despite considerable advances in surgery, radiation, and chemotherapy (temozolomide, TMZ), the prognosis for glioma has not significantly improved (2). With a median survival time of $12-15$ months, fewer than $3 \%$ of glioma patients live longer than 5 years after diagnosis (3-5). Because of the restricted anatomical location and absence of metastases outside the central nervous system (CNS), targeted gene therapy may provide a promising strategy to treat gliomas (6). Therefore, identification of target genes that drive tumorigenicity is essential for developing targeted therapy for

Correspondence to: Professor Zhao-Qian Liu, Department of Clinical Pharmacology, Xiangya Hospital, Central South University, Changsha, Hunan 410008, P.R. China

E-mail: liuzhaoqian63@126.com

Key words: glioma, FOXD1, proliferation, migration, prognostic value glioma (7-10). One promising family for gene targeting is the Forkhead-box (FOX) family. The FOX family consists of at least 43 transcription factors that regulate the expression of genes that support cell growth, proliferation and differentiation (11). Many FOX genes function as oncogenes. For example, FOXA1 is amplified and overexpressed in esophageal and lung adenocarcinomas (12). FOXO1 fused to PAX3 or PAX7 serve as prognostic indicators in alveolar rhabdomyosarcoma (13-15).

FOXD1 (also known as FREAC-4) is highly expressed in the kidney and controls cellularity in the renal capsule, a structure required for normal renal development (16-19). FOXD1 is also expressed in the brain and the retina and is necessary for normal development of the retina and optic chiasm $(20,21)$. FOXD1 has also been implicated as an oncogene, as it promotes breast cancer proliferation and chemotherapeutic drug resistance by targeting p27 (22). However, the role of FOXD1 in tumorigenesis and progression, particularly in glioma, is still limited.

In the present study, we first revealed the role of FOXD1 in glioma tumorigenesis and progression. We found that FOXD1 expression is upregulated and directly correlated with the glioma grade. Using FOXD1-siRNA, we determined that silencing FOXD1 expression inhibits cell proliferation and migration. Our results suggest that FOXD1 may be a potential therapy target for patients with glioma.

\section{Materials and methods}

Cell culture and transfection. Human glioma cell lines U87 and U251 were cultured in DMEM (C11995500BT, Gibco) supplemented with $10 \%$ fetal bovine serum (FBS, 10099-141, Gibco). Cells were cultured at $37^{\circ} \mathrm{C}$ in a humidified atmosphere of $5 \% \mathrm{CO}_{2}$. Trypsin-EDTA (0.25\%) (25200072, Gibco) was used to detach the cells from the flask. The FOXD1-siRNA and negative control siRNA (NC-siRNA) were purchased from Santa-Cruz Biotechnology (sc-60649; sc-637007) and Sigma. Cells were transfected using Lipofectamine ${ }^{\circledR}$ RNAiMAX reagent (13778150, Invitrogen) according to the protocol.

Glioma tumor specimens. All patients undergoing surgical treatment at the Hunan Cancer Hospital (Changsha, Hunan, 
China) for primary brain cancers between 2007 and 2013 were invited to participate in this institutional review boardapproved study. Seventy patients diagnosed with low grade glioma (LGG, n=36) or high grade glioma (HGG, n=34) tumors were included in the study. Tissue samples were collected from glioma patient tumors. Normal brain tissue $(n=20)$ was also obtained from patient with brain injury. The tissue samples were flash frozen in liquid nitrogen immediately after resection and stored at $-80^{\circ} \mathrm{C}$ for future processing.

RNA extraction and quantitative real-time PCR. Total RNA was extracted by TRIzol reagent according to the manufacturer's protocol. Two micrograms of RNA was reverse-transcribed into cDNAs using the Primescript RT reagent kit with gDNA Eraser (Takara Bio Inc., Japan). The PCR system was performed using SYBR Premix DimerEraser kit (Takara Bio Inc). The reactions were cycled 40 times $\left[95^{\circ} \mathrm{C}, 30 \mathrm{sec}\right.$, $\left(95^{\circ} \mathrm{C}, 5 \mathrm{sec} ; 55^{\circ} \mathrm{C}, 30 \mathrm{sec}\right.$; and $\left.\left.72^{\circ} \mathrm{C}, 30 \mathrm{sec}\right)\right]$ with fluorescence measurements. A melting curve was performed at the end of amplification cycles to verify the specificity of the PCR products. Primers used for real-time PCR were as follows: FOXD1, F: AAGAACCCGCTGGTGAAG; R: GTCCAGTAG TTGCCCTTGC. GAPDH, F: GAGTCAACGGATTTGGT CGT; R: TTGATTTTGGAGGGATCTCG. All of the determinations were performed in duplicate. The relative expression of FOXD1 mRNA was normalized to the expression level of GAPDH mRNA using the $2^{-\Delta \mathrm{Ct}}$ method.

Western blotting. Total cellular protein was extracted with RIPA. SDS-PAGE was performed with $50 \mu \mathrm{g}$ total cellular proteins using $10 \%$ gradient Tris-glycine gels. Primary antibodies used included anti-FOXD1 (WH0002297M1, Sigma-Aldrich LLC, USA), and anti-GAPDH (G8795, Sigma-Aldrich LLC). The bound antibodies were visualized using an enhanced chemiluminescence reagent (RPN2232, GE Healthcare, UK) and quantified by densitometry using ChemiDoc XRS+ image analyzer (Bio-Rad, USA). Densitometric analyses of bands were adjusted with GAPDH as loading control. Triplicate experiments with triplicate samples were performed.

MTS assay. Cells were collected in the logarithmic phase of growth and seeded into 96-well culture plates (1,000 cells/well). The cells were incubated in $100 \mu \mathrm{l}$ MTS reagent (1:9) for $1 \mathrm{~h}$. The absorbance values were measured at $490 \mathrm{~nm}$ by the BioTek ${ }^{\circledR}$ Eon (Synergy ${ }^{\mathrm{TM}}$, HT, USA). In the absence of cells, background absorbance of the medium was subtracted. Each assay was performed in triplicate.

Colony formation assay. U251 cells were collected in the logarithmic phase of growth and seeded in triplicate into 6-well plates at a density of 1,000 cells/well. Cells were cultured for 12 days at $37^{\circ} \mathrm{C}$ in an incubator with a $5 \% \mathrm{CO}_{2}$ atmosphere. The cells were then fixed with $4 \%$ paraformaldehyde for $30 \mathrm{~min}$ and stained with Giemsa (C0121, Beyotime, China) for 20 min. After washing with PBS several times, the cells were photographed with a camera (Canon, Japan) and the cell colonies were counted.

Wound healing assay. Cells ( $2 \times 10^{5}$ cells/well.) were seeded onto a 6 -well plate overnight. The confluent monolayers were scratched using sterile pipette tips and washed with phosphatebuffered saline (PBS) 3 times to remove detached cells. The cells were then transfected with siRNA for $36 \mathrm{~h}$. Photographs of the wounded areas were obtained using a Leica DMI3000 B inverted microscope (Leica, German). The migration rate was calculated as the ratio of the width of the scratch that remained cell-free after migration to the initial average width of the scratch. The size of the wounded areas was quantified using ImageJ Version 1.41o software (National Institutes of Health).

Immunofluorescent staining. Glioma cells were seeded into 6 -well plates and cultured with siRNA for $48 \mathrm{~h}$. The cells were then fixed with $4 \%$ paraformaldehyde for $10 \mathrm{~min}$ at room temperature, washed and stained with Hoechst 33258 (C0003, Beyotime) for $5 \mathrm{~min}$. Cells were observed under a Leica DMI3000 B inverted microscope equipped with ebq100-04 (Leica, Germany).

Statistical analysis. SPSS16.0 software was used for general statistics analyses. Comparisons between two experimental groups were performed using Student's t-test. Survival rate was calculated using the Kaplan-Meier method with the logrank test applied for comparison. All tests performed were two sided and the criterion for statistical significance was $\mathrm{p}<0.05$.

\section{Results}

High FOXD1 expression in glioma. The expression pattern of FOXD1 was evaluated in 70 glioma tissues and 20 normal brain tissues using quantitative real-time PCR (Q-PCR). FOXD1 expression was significantly higher in glioma tissues (LGG, $\mathrm{p}=0.047$; HGG, $\mathrm{p}=0.002$ ) compared with normal brain samples. FOXD1 expression was also higher in high grade glioma compared with low grade glioma ( $p=0.001$, Fig. 1A). Furthermore, the association between FOXD1 expression and clinicopathological parameters was analyzed in the present study. No significant association was observed between FOXD1 expression and patient age or gender (Table I). To further validate these results, we analyzed expression of FOXD1 in expression profiles (GSE4290 and GSE7696) acquired from the Gene Expression Omnibus (GEO, http:// www.ncbi.nlm.nih.gov/geo/) database, and glioma datasets acquired from The Cancer Genome Atlas (TCGA; http:// cancergenome.nih.gov/). We found that expression of upregulated FOXD1 (>2-fold upregulated) expression was significantly higher in malignant gliomas compared to lower grade gliomas and non-tumor brain tissue and directly correlated with the glioma grade in GSE4290 dataset (Fig. 1B). Analysis of the GSE7696 data and TCGA revealed that FOXD1 have $>2$-fold upregulation at the transcription level and were greatly increased in malignant gliomas when compared to non-tumor brain tissue (Fig. 1C and D). These results suggest that increased FOXD1 expression correlates with glioma tumor grade.

Prognostic value of FOXD1 expression in gliomas. To determine the association between FOXD1 expression and clinical outcome, Kaplan-Meier analysis was conducted for expression profiles (GSE4290 and GSE7696) and the TCGA data. The analysis showed no significant difference in outcome between 

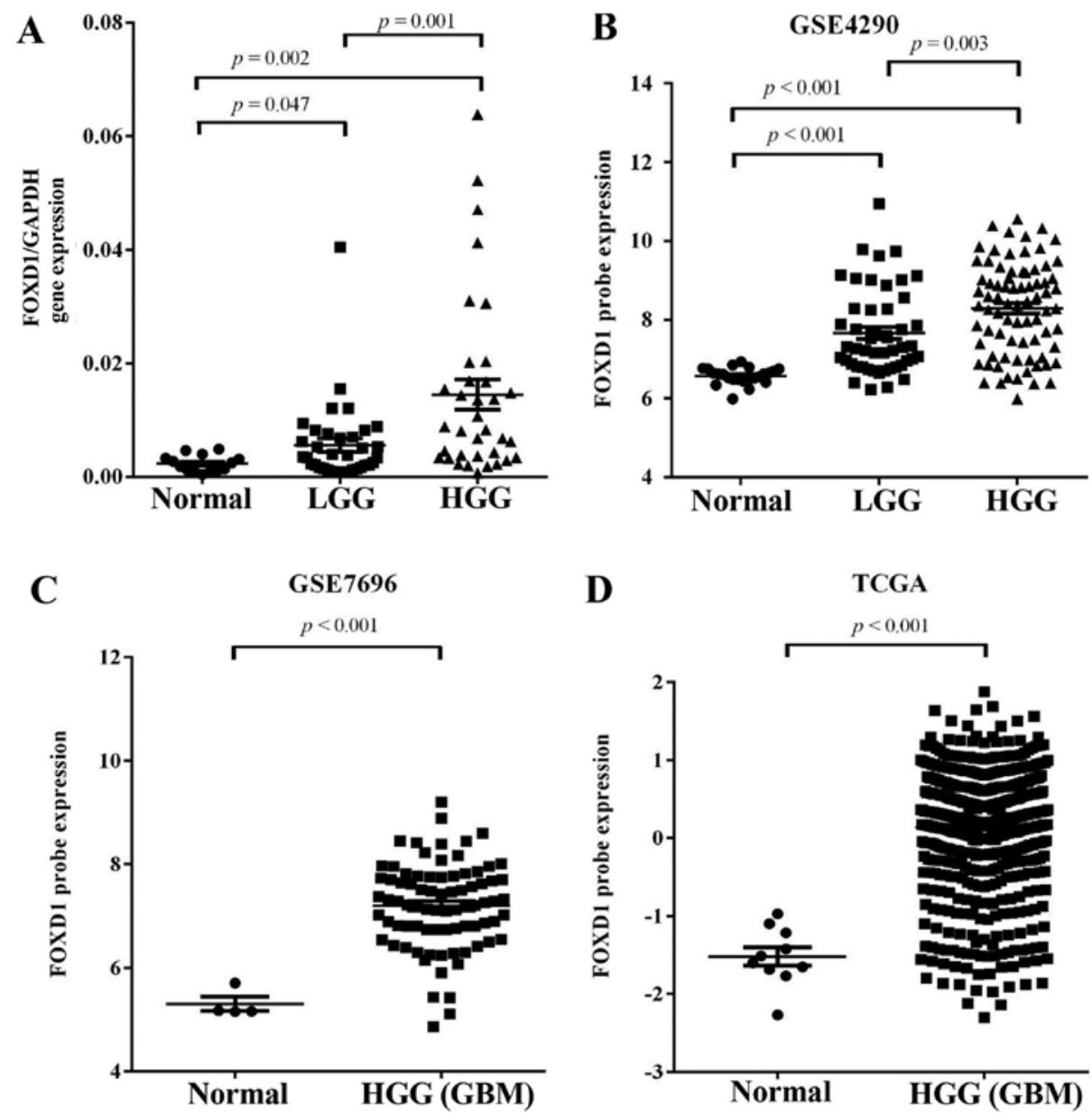

Figure 1. High Foxd1 expression in glioma. (A) FOXD1 was upregulated and directly correlated with the glioma grade. Data analysis showed significant differences in GSE4290 (B), GSE7679 (C) and TCGA (D) between the glioma tissues and normal brain samples.

Table I. Correlation between FOXD1 expression and glioma clinicopathological features in 70 patients.

FOXD1 expression levels

Clinicopathological

$\mathrm{N} \%$

High expression

Low expression

Ratio

p-value

features

High/low

\begin{tabular}{llllll}
\hline Gender & & & & & \\
Male & $48(68.57)$ & 14 & 35 & 0.4 & 0.092 \\
Female & $22(31.43)$ & 10 & 12 & 0.833 & \\
Age years & & & & & \\
$<45$ & $44(62.85)$ & 13 & 15 & 0.419 & 0.056 \\
$\geq 45$ & $26(37.14)$ & 11 & & & \\
Grade & & & 30 & 0.2 & 0.002 \\
Low (I+II) & $36(51.42)$ & 18 & 16 & 1.125 & \\
High (III+IV) & $34(48.58)$ & & & & \\
\hline
\end{tabular}

patients with high FOXD1 expressing and low FOXD1 expressing gliomas for both gene expression profiles and the TCGA datasets (Fig. 2). The clinical outcome of those patients with high FOXD1 expression was observed to be better than those with a low FOXD1 expression. Even so,
FOXD1 expression may not serve as a prognostic factor of glioma patients.

SiRNA inhibits FOXD1 expression efficiently in human glioma cell lines. In order to investigate the role of FOXD1 in glioma, 

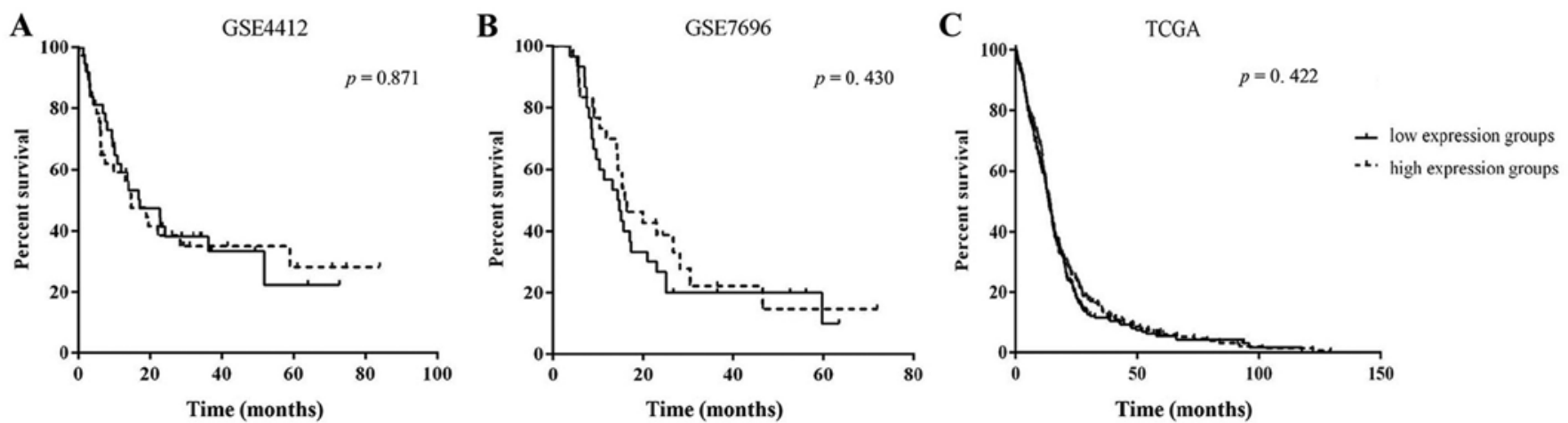

Figure 2. Prognostic value of FOXD1 expression in gliomas. Kaplan-Meier survival analysis for patients with three data. There is no significant difference between the high FOXD1 expression and the low FOXD1 expression patients with glioma in GSE4412, GSE7696 and TCGA datasets.
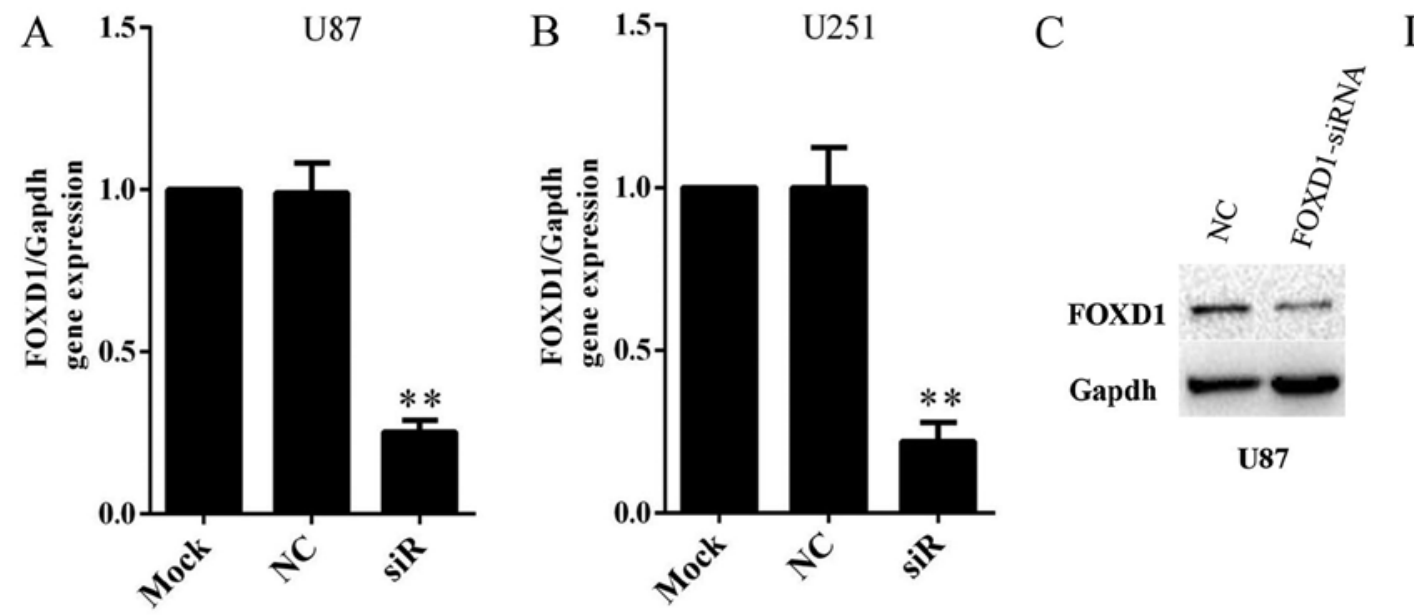

D

Figure 3. SiRNA inhibits FOXD1 expression efficiently in human glioma cell lines. Treatment with FOXD1-siRNA led to an $28 \%$ reduction in the expression of FOXD1 mRNA and evident depletion of the expression of FOXD1 protein in U87 (A and C); U251 (B and D). ${ }^{* *} \mathrm{P}<0.01$.

we knockdown expression of FOXD1 using a FOXD1-siRNA. Malignant human glioma cell lines U87 and U251 were treated with FOXD1-siRNA or NC-siRNA. Treatment with FOXD1-siRNA significantly reduced FOXD1 mRNA expression by $\sim 80 \%$ and nearly depleted protein expression in U87 (Fig. 3A and C) and U251 (Fig. 3B and D) cells. Therefore, the present results demonstrated that a highly efficient knockdown of FOXD1 expression at the mRNA and protein levels was achieved after transfection.

Knockdown of FOXD1 suppresses proliferation and promotes apoptosis in glioma cells. To investigate the effect of FOXD1 silencing on glioma cell proliferation, U87 and U251 cells transfected with FOXD1-siRNA or NC-siRNA were analyzed by MTS assay. Proliferation of U87 cells treated with FOXD1siRNA began to decrease $72 \mathrm{~h}$ after treatment. On day 4 , proliferation of cells treated with FOXD1-siRNA was significantly reduced compared to those treated with NC-siRNA or non-treated cells $(\mathrm{p}<0.001$; Fig. $4 \mathrm{~A})$. These results are consistent with U251 cells ( $<<0.001$; Fig. 4B). Moreover, no difference was seen between NC-siRNA treated cells and Mock cells. The relatively long-term effects of FOXD1 knockdown on glioma cell proliferation were also examined using a colony formation assay. As shown in Fig. 4C and D, silencing of FOXD1 expression in U251 cells substantially reduced colony formation $(\mathrm{p}<0.001)$.

In addition to unlimited proliferation and elevated clonogenic capacity, evading apoptosis is also essential for tumor initiation and development. To determine whether the reduction in cell number following FOXD1 knockdown is due in part to cell apoptosis, we treated U251 cells with FOXD1-siRNA or NC-siRNA and stained them with Hoechst 33258 to evaluate cell viability. Apoptotic bodies containing nuclear fragments were generated in transfected FOXD1-siRNA group (Fig. 4E), suggesting that FOXD1 knockdown may induce cell apoptosis in glioma cells.

Silencing effect of FOXD1 on migration in U251 cells. We investigated the effect of FOXD1 silencing on cell migration. FOXD1 knockdown markedly reduced glioma cell migration $36 \mathrm{~h}$ after transfection with the FOXD1-siRNA (Fig. 5A). Migration rates were significantly lower for FOXD1-siRNA treated cells compared to non-treated and NC-siRNA treated cells ( $p=0.002$ ) (Fig. 5B). No significant differences were found between Mock and NC-siRNA treated cells. These results suggest that FOXD1 contributes to glioma cell migration. 

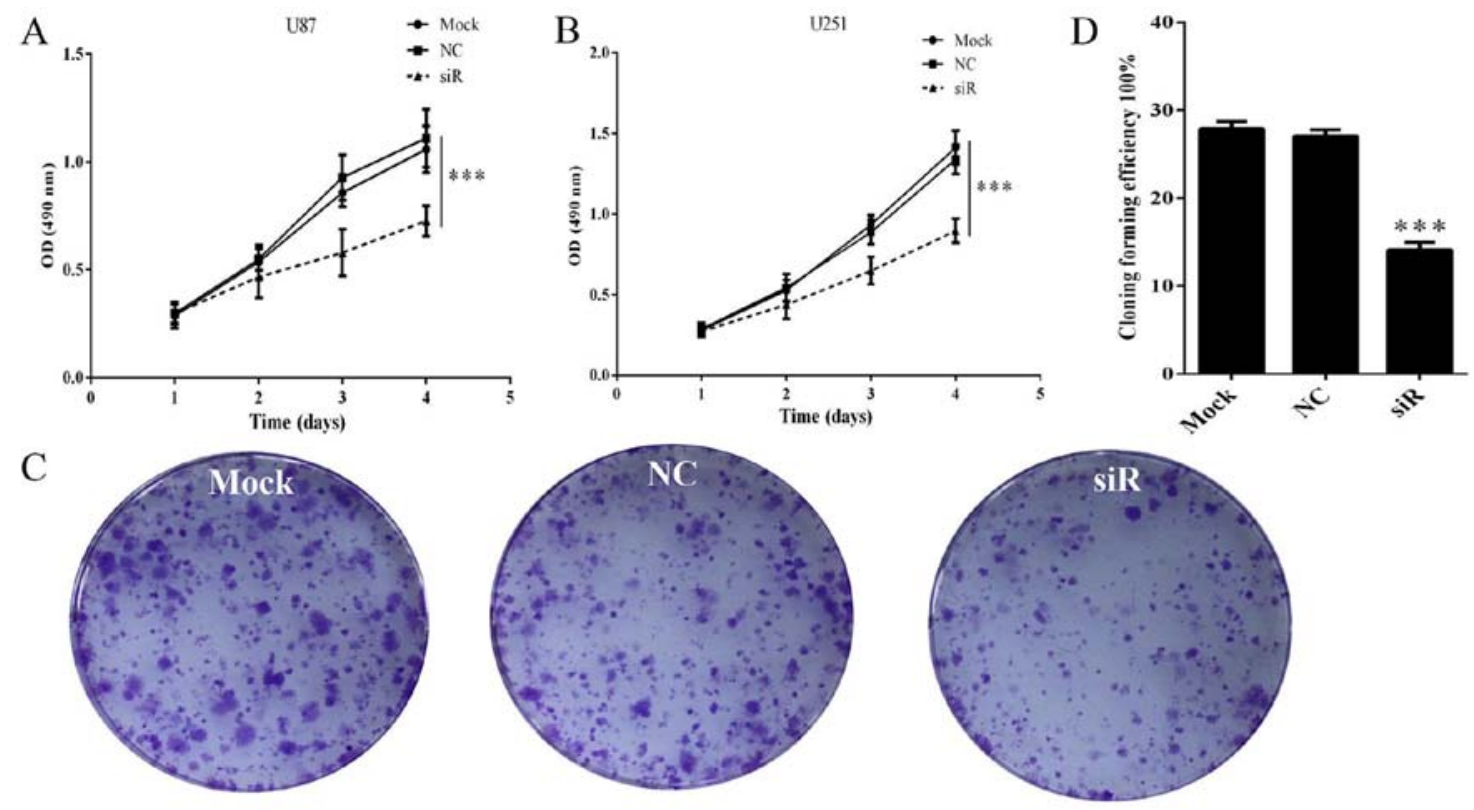

E
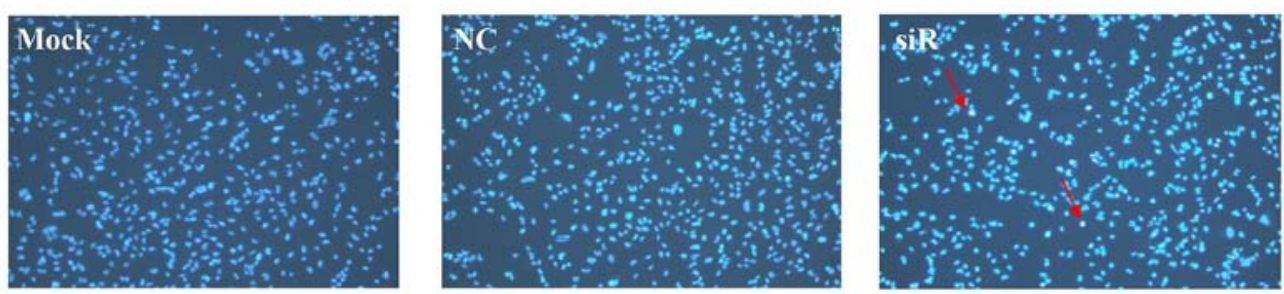

Figure 4. Knockdown of FOXD1 suppresses proliferation and promotes apoptosis in glioma cells. (A and B) MTS assay. Compared to that of Mock and NC-siRNA groups, the absorbance value in FOXD1-siRNA group was remarkably reduced in U87, U251. (C and D) Colony formation assay. Silencing of FOXD1 expression in U251 cells resulted in a substantial reduction in colony formation as compared to Mock or NC-siRNA. (E) Immunofluorescent staining. Apoptotic bodies containing nuclear fragments were generated in transfected FOXD1-siRNA group. ${ }^{* * * *} \mathrm{P}<0.001$.
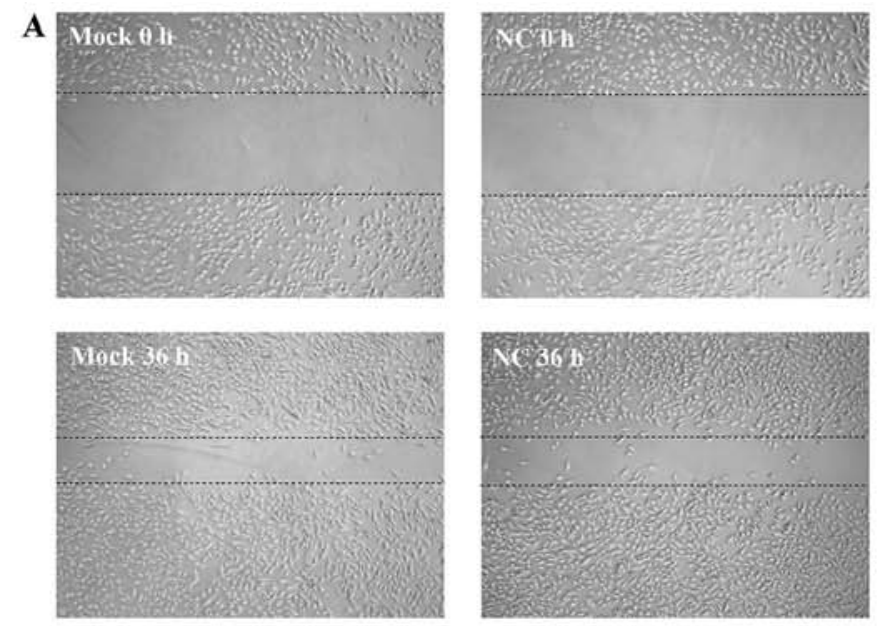
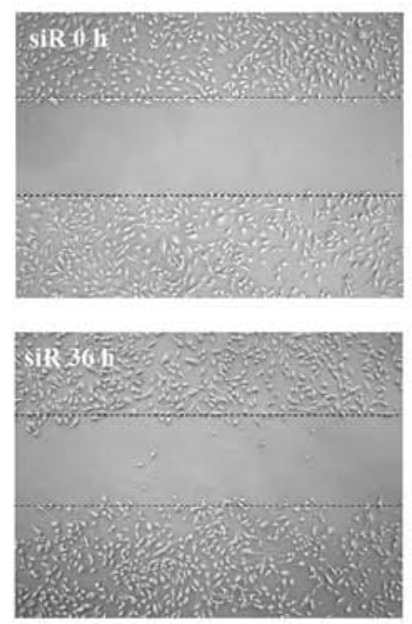

Figure 5. Silencing effect of FOXD1 on migration in U251 cells. (A) Scratch-wound assay. The silencing effect of FOXD1 markedly reduced glioma cell migration. (B) Migration rates were significantly lower for FOXD1-siRNA treated cells compared to non-treated and NC-siRNA treated cells. ${ }^{* *} \mathrm{P}<0.01$.

\section{Discussion}

Despite advances in standard treatments of glioma, little progress has been made in patient outcome. This is due in part to the non-specific nature of these treatments. Thus, alternative therapies that specifically target tumor-specific genes may provide a promising alternative treatment to the current standards of care. This study identified FOXD1 as a potential target for the development of tumor targeted therapies.

We show that FOXD1 is upregulated in glioma tissues compared to normal brain tissues and that silencing FOXD1 expression inhibits glioma cell proliferation and migration rates. Blocking FOXD1 expression also generated apoptotic bodies containing nuclear fragments suggesting that FOXD1 
promotes cell death. Taken together, the results suggest that FOXD1 functions as an oncogene in glioma.

Forkhead box (FOX) proteins, an evolutionarily conserved family of transcriptional regulators, mediate a wide range of biological processes, such as proliferation, metabolism, differentiation, apoptosis, and migration (23-27), and take part in the onset and progression of tumors (28). Some studies show that FOXD1 is related to organization development $(19,29)$, cell reprogramming (30), cell differentiation (31). These results are consistent with previous studies that have shown that FOX transcription factors promote cancer cell migration and proliferation.

Our study also parallels the previous studies that found FOXD1 promotes cell growth. In 2015, Zhao et al (22) showed that FOXD1 promotes the cell cycle progression by inducing $\mathrm{G} 1 \rightarrow \mathrm{S}$ transition, suggesting that FOXD1 induces $\mathrm{G} 1 \rightarrow \mathrm{S}$ transition by down-regulation of p27 expression. Further investigation into the mechanisms underlying FOXD1 is needed to determine how FOXD1 supports cell proliferation and other oncogenic activities in glioma.

In order to confirm the relationship between FOXD1 and its prognosis, we collected the datasets GSE4412, GSE7696 and TCGA. Kaplan-Meier analysis showed no significant differences in GSE4412 or GSE7696 between the high FOXD1 expression and low FOXD1 expression groups in patients with glioma, and it is the same as in TCGA data. FOXD1 expression may not serve as a prognostic factor of glioma patients.

In conclusion, our results show that FOXD1 expression is highly expressed in malignant gliomas and directly correlates with glioma grade. Kaplan-Meier analysis showed FOXD1 expression may not serve as a prognostic factor of glioma patients. However, reduced expression of FOXD1 inhibits glioma cell proliferation, cell survival and migration. These findings implicate FOXD1 as an oncogene in glioma that could potentially serve as a therapeutic target for glioma treatment.

\section{Acknowledgements}

This study was supported by the National High-tech R\&D Program of China (863 Program) (2012AA02A517), National Natural Science Foundation of China (81373490, 81573508, 81573463), and Hunan Provincial Science and Technology Plan of China (2015TP1043), and Open Foundation of Innovative Platform in University of Hunan Province of China (2015-14).

\section{References}

1. Schucht P, Beck J, Seidel K and Raabe A: Extending resection and preserving function: Modern concepts of glioma surgery. Swiss Med Wkly 145: w14082, 2015.

2. Haque A, Banik NL and Ray SK: Emerging role of combination of all-trans retinoic acid and interferon-gamma as chemoimmunotherapy in the management of human glioblastoma. Neurochem Res 32: 2203-2209, 2007.

3. Ohgaki H: Epidemiology of brain tumors. Methods Mol Biol 472: 323-342, 2009

4. Stupp R, Mason WP, van den Bent MJ, Weller M, Fisher B, Taphoorn MJ, Belanger K, Brandes AA, Marosi C, Bogdahn U, et al; European Organisation for Research and Treatment of Cancer Brain Tumor and Radiotherapy Groups; National Cancer Institute of Canada Clinical Trials Group: Radiotherapy plus concomitant and adjuvant temozolomide for glioblastoma. N Engl J Med 352: 987-996, 2005.

5. Wen PY and Kesari S: Malignant gliomas in adults. N Engl J Med 359: 492-507, 2008.
6. Pulkkanen KJ and Yla-Herttuala S: Gene therapy for malignant glioma: Current clinical status. Mol Ther 12: 585-598, 2005.

7. Weigel D, Jürgens G, Küttner F, Seifert E and Jäckle H: The homeotic gene fork head encodes a nuclear protein and is expressed in the terminal regions of the Drosophila embryo. Cell 57: 645-658, 1989.

8. Lai E, Prezioso VR, Smith E, Litvin O, Costa RH and Darnell JE Jr: HNF-3A, a hepatocyte-enriched transcription factor of novel structure is regulated transcriptionally. Genes Dev 4: 1427-1436, 1990.

9. Lai E, Prezioso VR, Tao WF, Chen WS and Darnell JE Jr: Hepatocyte nuclear factor 3 alpha belongs to a gene family in mammals that is homologous to the Drosophila homeotic gene fork head. Genes Dev 5: 416-427, 1991.

10. Kaestner KH, Knochel W and Martinez DE: Unified nomenclature for the winged helix/forkhead transcription factors. Genes Dev 14: 142-146, 2000.

11. Katoh M and Katoh M: Human FOX gene family (Review). Int J Oncol 25: 1495-1500, 2004.

12. Lin L, Miller CT, Contreras JI, Prescott MS, Dagenais SL, Wu R, Yee J, Orringer MB, Misek DE, Hanash SM, et al: The hepatocyte nuclear factor 3 alpha gene, HNF3alpha (FOXA1), on chromosome band $14 \mathrm{q} 13$ is amplified and overexpressed in esophageal and lung adenocarcinomas. Cancer Res 62: 5273-5279, 2002.

13. Sorensen PH, Lynch JC, Qualman SJ, Tirabosco R, Lim JF, Maurer HM, Bridge JA, Crist WM, Triche TJ and Barr FG: PAX3-FKHR and PAX7-FKHR gene fusions are prognostic indicators in alveolar rhabdomyosarcoma: A report from the children's oncology group. J Clin Oncol 20: 2672-2679, 2002.

14. Hillion J, Le Coniat M, Jonveaux P, Berger R and Bernard OA: AF6q21, a novel partner of the MLL gene in $t(6 ; 11)(\mathrm{q} 21 ; \mathrm{q} 23)$, defines a forkhead transcriptional factor subfamily. Blood 90: 3714-3719, 1997.

15. Parry P, Wei Y and Evans G: Cloning and characterization of the $t(X ; 11)$ breakpoint from a leukemic cell line identify a new member of the forkhead gene family. Genes Chromosomes Cancer 11: 79-84, 1994.

16. Hatini V, Tao W and Lai E: Expression of winged helix genes, BF-1 and BF-2, define adjacent domains within the developing forebrain and retina. J Neurobiol 25: 1293-1309, 1994.

17. Pierrou S, Hellqvist M, Samuelsson L, Enerbäck $S$ and Carlsson P: Cloning and characterization of seven human forkhead proteins: Binding site specificity and DNA bending. EMBO J 13: 5002-5012, 1994.

18. Hatini V, Huh SO, Herzlinger D, Soares VC and Lai E: Essential role of stromal mesenchyme in kidney morphogenesis revealed by targeted disruption of Winged Helix transcription factor BF-2. Genes Dev 10: 1467-1478, 1996.

19. Levinson RS, Batourina E, Choi C, Vorontchikhina M, Kitajewski J and Mendelsohn CL: Foxd1-dependent signals control cellularity in the renal capsule, a structure required for normal renal development. Development 132: 529-539, 2005.

20. Herrera E, Marcus R, Li S, Williams SE, Erskine L, Lai E and Mason C: Foxd1 is required for proper formation of the optic chiasm. Development 131: 5727-5739, 2004.

21. Gumbel JH, Patterson EM, Owusu SA, Kabat BE, Jung DO, Simmons J, Hopkins T and Ellsworth BS: The forkhead transcription factor, Foxd1, is necessary for pituitary luteinizing hormone expression in mice. PLoS One 7: e52156, 2012.

22. Zhao YF, Zhao JY, Yue H, Hu KS, Shen H, Guo ZG and Su XJ: FOXD1 promotes breast cancer proliferation and chemotherapeutic drug resistance by targeting p27. Biochem Biophys Res Commun 456: 232-237, 2015.

23. Wang Z, Banerjee S, Kong D, Li Y and Sarkar FH: Downregulation of Forkhead Box M1 transcription factor leads to the inhibition of invasion and angiogenesis of pancreatic cancer cells. Cancer Res 67: 8293-8300, 2007.

24. Kaneda H, Arao T, Tanaka K, Tamura D, Aomatsu K, Kudo K, Sakai K, De Velasco MA, Matsumoto K, Fujita Y, et al: FOXQ1 is overexpressed in colorectal cancer and enhances tumorigenicity and tumor growth. Cancer Res 70: 2053-2063, 2010.

25. Ray PS, Wang J, Qu Y, Sim MS, Shamonki J, Bagaria SP, Ye X, Liu B, Elashoff D, Hoon DS, et al: FOXC1 is a potential prognostic biomarker with functional significance in basal-like breast cancer. Cancer Res 70: 3870-3876, 2010.

26. Paik JH, Kollipara R, Chu G, Ji H, Xiao Y, Ding Z, Miao L, Tothova Z, Horner JW, Carrasco DR, et al: FoxOs are lineagerestricted redundant tumor suppressors and regulate endothelial cell homeostasis. Cell 128: 309-323, 2007. 
27. Balli D, Ustiyan V, Zhang Y, Wang IC, Masino AJ, Ren X, Whitsett JA, Kalinichenko VV and Kalin TV: Foxm 1 transcription factor is required for lung fibrosis and epithelial-tomesenchymal transition. EMBO J 32: 231-244, 2013.

28. Myatt SS and Lam EW: The emerging roles of forkhead box (Fox) proteins in cancer. Nat Rev Cancer 7: 847-859, 2007.

29. Humphreys BD, Lin SL, Kobayashi A, Hudson TE, Nowlin BT, Bonventre JV, Valerius MT, McMahon AP and Duffield JS: Fate tracing reveals the pericyte and not epithelial origin of myofibroblasts in kidney fibrosis. Am J Pathol 176: 85-97, 2010.
30. Koga M, Matsuda M, Kawamura T, Sogo T, Shigeno A, Nishida E and Ebisuya M: Foxd1 is a mediator and indicator of the cell reprogramming process. Nat Commun 5: 3197, 2014.

31. Fetting JL, Guay JA, Karolak MJ, Iozzo RV, Adams DC, Maridas DE, Brown AC and Oxburgh L: FOXD1 promotes nephron progenitor differentiation by repressing decorin in the embryonic kidney. Development 141: 17-27, 2014. 